\title{
A study of stochastic optimization problem for humanitarian supply chain management
}

\author{
Jing SUN*, Ru CHAI* and Koichi NAKADE* \\ * Nagoya Institute of Technology \\ Department of Architecture, Civil Engineering and Industrial Management Engineering, \\ Gokiso-cho, Showa-ku, Nagoya, Aichi, 466-8555 Japan \\ E-mail: sun.jing@nitech.ac.jp
}

Received: 27 November 2017; Revised: 25 February 2018; Accepted: 2 March 2018

\begin{abstract}
Due to the frequency increase of natural disasters such as the earthquake and tsunami, the humanitarian supply chain management (SCM) became an important topic for scientific research. This paper proposes a two-stage stochastic model to optimize the cost of the whole relief process under uncertainty about demand, pre-positioned stocks and the condition of the transportation network. Many factors are considered such as fleet size, route availability and the extra stocking amount. The model also requires that in each scenario the satisfied proportion should be at least meet the lowest satisfaction value, which is decided by the properties of each area and the event. A case study application is used to illustrate the model and how it supports an emergency relief strategy.
\end{abstract}

Keywords : Humanitarian SCM, Stock estimation, Scenario analysis, Stochastic optimization problem, TOPSIS method

\section{Introduction}

Humanitarian supply chain management is the creation through which communities reduce vulnerability to hazards and cope with disasters. The events covered by disaster management include acts of terrorism, industrial sabotage, fire, natural disasters such as earthquakes and hurricanes, public disorder, industrial accidents, and communication failures. As an advanced humanitarian time series scheduling problem (Fig. 1), Duran (2012) mentioned that the disaster management is comprised of four sequential stages occurring during the life cycle of the disaster- Mitigation, Preparedness, Response and Recovery. During the mitigation stage actions are taken to prevent the onset of the disaster or moderate its effects. The preparedness stage aims at decreasing the response time by purchasing the relief commodities in advance and pre-positioning of needed supplies. In the response stage, the disaster mitigations plans are activated and the emergency supplies are distributed. The last step is the recovery stage, which includes retrieving the victims, rebuilding the infrastructure, and mitigating damages in the disaster areas.

Application of operations research in disaster logistics management has been one of the main issues in recent decades. Supply chain and logistics management are recently being used as analytical tools and techniques to provide efficient and effective relief to people who need help in devastated areas with optimized functions and activities. According to Carmen and Mark (2012), pre-positioning provides numerous benefits to relief organizations. First, relief commodities stored in the distribution center reduce the response time assisting disaster victims. Second, through the advanced procurement of sup-plies humanitarian organizations can consider local, regional and international suppliers, so they can get better prices for the relief commodities. Thirdly, by buying in larger volumes humanitarian organizations can increase their purchasing power and take advantage of lower bulk prices. The aim of response to disasters in humanitarian relief chains is to provide quick relief to affected areas in order to minimize the death and pain of people. In this paper, we focus on the preparedness and response stages, specifically the pre-positioning of the relief commodities and dispatching the relief commodities during the progression of the event. 


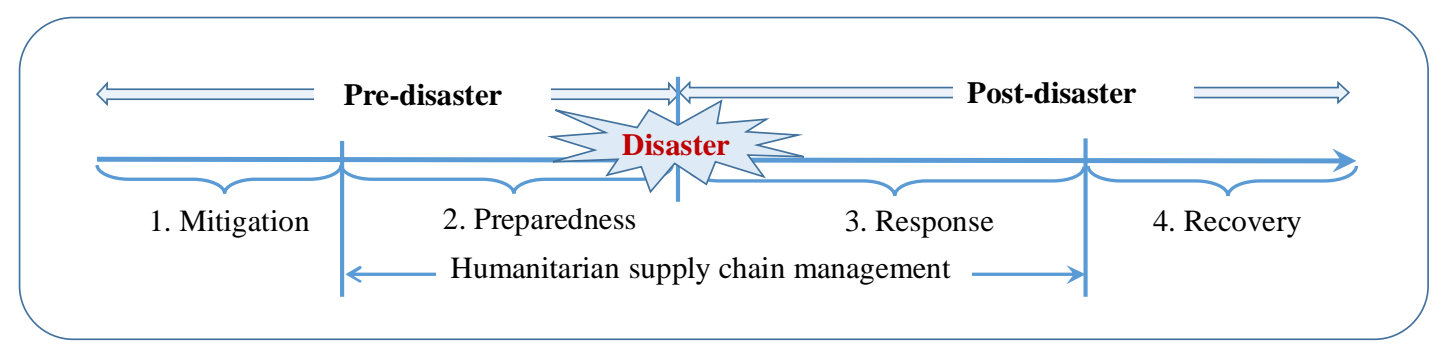

Fig. 1 An advanced humanitarian time series scheduling

However, according to Goncalves (2011), many humanitarian decision makers often make decisions by over-reliance on the past experiences. Failure to create a plan could lead to human mortality, lost revenue, and damage to assets. This motivates this paper to study the stochastic models that can deal with the urgent complexity and uncertainty to help these decision makers. Due to the increased frequency and severity of disasters around the world in recent decades, the disaster management field have been the subject of growing public concern and research interest. (Smith, et al., 2009)

Several researchers have addressed problems of post-event distribution of emergency supplies. Important examples include the work of Haghani and Oh (1996), Sheu and Hsu (1997), Houming et al.,(2008) and Yan and Shi (2009). These models assume that the characteristics of the event, the resulting demands for the supplies, the locations and the available quantities of those supplies, and the condition of the transportation network are known. Haghani and Oh (1996) develop a multi-commodity, multi-mode network flow model to help emergency response managers organize detailed load plans for dispatching the relief commodities after a disaster.

Recently, two-stage stochastic models have been successfully used in humanitarian logistics and disaster management as they allow the modeler to represent pre-event and post-event phases together via the two stages decision variables. Barbarosoglu and Arda (2004) firstly develop a two-stage stochastic model for both pre-event and post-event stages in disaster response, considering the uncertainties in available supplies and demands by generating a set of scenarios. Related work has been done by Ozdamar et al. (2004), who created a dynamic model to generate multi-period vehicle routes and schedules along with commodity assignments.

The above papers do not consider route or link probability in their transportation plans. Route probability, which relates to road conditions, represents one of the uncertainty factors that occur after a disaster strikes. Therefore, it is very important to consider route probability into the model. Opit and Nakade (2016) generate all possible path combinations, which is also the scenarios that we use in this paper. A mixed-integer programming model which limited by the route condition and budget is developed to maximize the amount of relief supplies sent to disaster areas.

In this study, rather than just focus on routing problem, we also want to make a proper plan both for the Preparedness phase (Stocking Estimation) and the Response Phase (Dispatching Plan). At the same time, many factors should be taken into consideration such as the available amount of relief commodities, available vehicle's numbers, or even how to reduce the regional satisfied differences and so on.

\section{A two-stage stochastic model for disaster management}

A two-stage model is formulated which combines decision on stocking levels for emergency supplies with the distribution of those supplies to multiple demand locations after an event, with uncertainty about demand, survival of pre-positioned stocks and the condition of the transportation network after the disaster. The whole structure of this 2-stage model can be demonstrated in Fig.2.

In pre-disaster period (stage 1), we want to estimate the stocking amount which limits by the demand of each disaster area, the route condition, capacity of the distribution center. In the post-disaster period (stage 2), in order to get a detailed dispatching plan, we minimize the total cost by the limited stocking relief amounts, route conditions, vehicles numbers, demands and the lowest satisfied degree.

\subsection{Assumptions of the model}

I. The uncertainty of demands from all disaster areas is reflected by probabilistic scenarios, and the demand information under each scenario is supposed accurately.

II. It is assumed that the distribution centers' number and location, vehicles' type and number are decided by the local authorities.

III. As the number of vehicles is limited, the relief demands from all the affected areas cannot be guaranteed to be satisfied completely in the allocation process.

IV. In making transportation plan for vehicles, each vehicle is required to return to its departure position after 


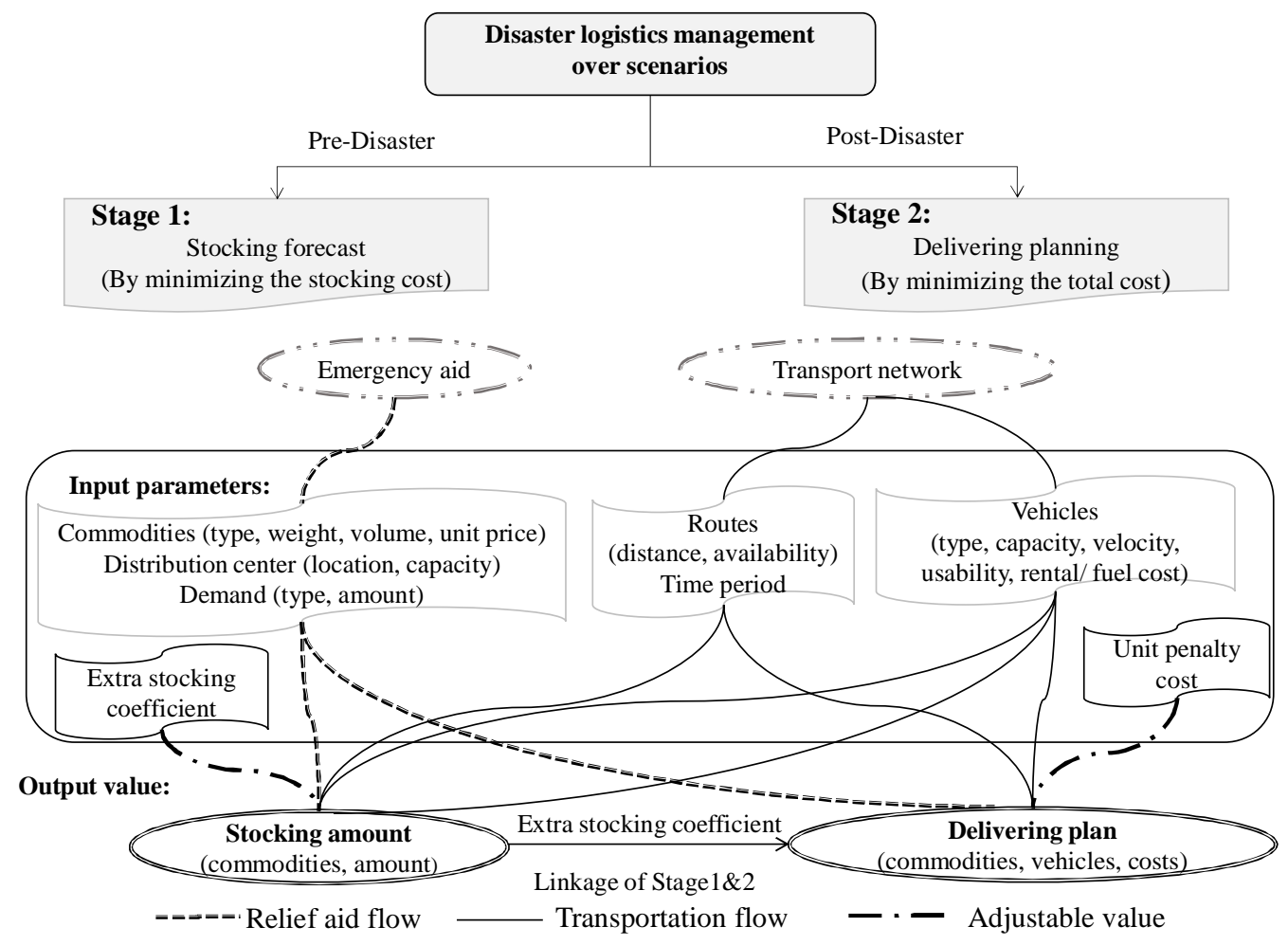

Fig. 2 Structure of the disaster logistics management mode

finishing its current mission.

V. It is supposed that helicopters can serve all of the disaster areas.

\subsection{Notations of the model}

The full mathematical model uses the following notations.

\section{Indices and sets}

$A$ : the set of commodities

$I$ : the set of distribution centers

$J$ : the set of disaster areas

$M$ : the set of vehicle types

$S$ : the set of scenarios

$f_{1}(s)$ : The set of sub-scenarios during time period 1

$T$ : the set of time periods

\section{Parameters}

$C A P_{i}$ : Capacity of distribution center $i, \quad i \in I$

$P C_{a}$ : A unit procurement cost of commodity $a, a \in A$

$w_{a}$ : Unit weight of commodity type $a, a \in A$

$c_{a}$ : Unit volume of commodity type $a, a \in A$

$\gamma_{a}$ : Degree of importance of commodity type $a, a \in A$

$$
\left(0<\gamma_{a}<1 ; \sum_{a} \gamma_{a}=1\right)
$$

$\pi_{a}$ : Penalty coefficient of unsatisfied demand typed $a$

$\alpha_{a j}$ : The lowest satisfied degree of commodity type $a$ in disaster area $j, a \in A, j \in J$

$v w^{m}:$ Weight capacity of vehicle $m, m \in M$

$v c^{m}$ : Volume capacity of vehicle $m, m \in M$

$v^{m}$ : The average velocity of vehicle $m, m \in M$

$T C_{m}$ : The transportation cost per kilometer of vehicle $m$

$Q C_{m}:$ The cost to rent a vehicle of type $m$ in the post-disaster period

$N V_{i m}$ : Available number of vehicles of type m for distribution center $i$

$N_{i m}$ : Maximum available transportation times of using $N V_{i m}$ vehicles of type $\mathrm{m}$ for each distribution center $i$

$L_{i j}$ : The distance from distribution center $i$ to disaster area $j, i \in I, j \in J$ 
$P_{S}$ : Probability of scenario $s, s \in S$

$D_{a j}^{s}$ : Amount of demanded commodity type $a$ at disaster area $j$ in scenario $s, s \in S, j \in J$

$R_{i j m t}^{\mathrm{S}}=\left\{\begin{array}{lr}1, j \text { is reachable from } i \text { by } m \text { at } t \text { in } s \\ 0, & \text { otherwise }\end{array}\right.$

$Z_{\mathrm{ij}}^{\mathrm{m}}=\left\{\begin{array}{lr}1, j \text { is reachable from } i \text { by } m \text { at } t \text { in } s \\ 0, & \text { otherwise }\end{array}\right.$

$i \in I, j \in J, s \in S, m \in M, t \in T$

$M$ : A very large positive number

$\beta$ : Extra stocking coefficient

$\eta$ : The unit penalty coeffcient

$\delta$ : The maximum of response time limit from distribution center to disaster area

\section{Decision variables in stage 1}

$X_{\text {aijmt }}^{S}$ : The amount of commodity type $a$ dispatched from distribution center $i$ to disaster area $j$ by vehicle $m$ at period $t$ in scenario $s$

$U D_{a j t}^{s}:$ Amount of unsatisfied demand of commodity type $a$ at disaster area $j$ at time $t$ in scenario $s$

STOC $_{a i}$ : The stocking amount of commodity typed $a$ in distribution center $i$

$N_{i j m t}^{S}$ : Number of vehicle $m$ moved from distribution $i$ to disaster area $j$ at period $t$ in scenario $s$

\section{Added variables in stage 2}

$Q V_{m}^{s}:$ Additional vehicle numbers of type $m$ in scenario $s$

$Q_{i m}^{S}$ : Available transportation times for $Q V_{i m}^{S}$ vehicles

\subsection{Stage 1 - stocking forecast}

In stage 1, we are going to estimate the stocking amount which limits by the demand of each disaster area, the route condition, capacity of the distribution center and the lowest satisfied degree of each disaster area.

In this model, the objective is to minimize the total cost under the constraint to satisfy the victims. So in this stage, we add an extra stocking coefficient $\beta$, which is used as adjusting the stocking level. $\beta$ is also an important factor to link stage 1 and stage 2 .

\subsubsection{Scenarios generation for stage 1}

To take uncertainty into account, we propose a set of scenarios based on the route availability, which is shown in Table 1 . In the relief process, some disrupted roadway may be repaired in the next time period.

Table 1 shows the scenarios generation of 2 time periods. We suppose that the number of the routes is $n$, number of disrupted routes in $1^{\text {st }}$ time period is $k$, number of repaired routes is $l$.

In the 1st time period, the probability of each route to be disrupted is $q_{1}$; in the 2nd time period the probability of each disrupted route to be repaired is $q_{2}$. Therefore, the probability of routes being available for each scenario $s$ (denoted by $P_{s}$ ) is calculated as follows:

$$
\begin{gathered}
P_{1}\left(\mathrm{~s}_{1}\right)=q_{1}{ }^{k} \cdot\left(1-q_{1}\right)^{n-k} ; \\
P_{2}\left(s \mid \mathrm{s}_{1}\right)=q_{2}{ }^{l} \cdot\left(1-q_{2}\right)^{k-l} ; \\
P_{S}=P_{1}\left(\mathrm{~s}_{1}\right) \cdot P_{2}\left(s \mid \mathrm{s}_{1}\right), \text { where, } \mathrm{s}_{1}=f^{1}(s) \text { and } s \in S .
\end{gathered}
$$

Each $s_{1} \in S$ means the route condition in time period 1, and $S$ is the set of the scenarios during the whole dispatching process. To understand the generation of the scenarios clearly, here is a sample in Table 1.

In Table 1, a binary code represents the availability of each route at one point in time, where 0 means the route is unavailable and 1 means the route is available. It is assumed that every available route during period 1 remains available during period 2. For instance, the route condition of the scenario 67 (s67) was changed from period 1 to period 2 as $(0,0,0,0,0,1) \rightarrow(0,0,0,1,0,1)$, which means that the fourth route disrupted in perod 1 is available in period 2 , whereas the first, second, third and fifth routes are disrupted in both periods 1 and 2 .

In this case study, the number of routes is $n=6$. The possible scenario for period 1 can be formulated as the combination of routes available (Number of scenarios in period 1 is $2^{6}=64$.) The number of possible scenarios in period 2 can be calculated by

$$
\sum_{\mathrm{k}=0}^{\mathrm{n}} \sum_{\mathrm{l}=0}^{\mathrm{k}}\left(\begin{array}{l}
\mathrm{n} \\
\mathrm{k}
\end{array}\right) \times\left(\begin{array}{l}
\mathrm{k} \\
\mathrm{l}
\end{array}\right)=\sum_{\mathrm{k}=0}^{\mathrm{n}}\left(\begin{array}{l}
\mathrm{n} \\
\mathrm{k}
\end{array}\right) 2^{\mathrm{k}}=3^{\mathrm{n}}=3^{6}=729 .
$$


Table 1 Sample of scenarios generation

\begin{tabular}{|c|c|c|c|}
\hline $\begin{array}{c}s_{1} \\
(\text { Scenarios in } t 1)\end{array}$ & $\begin{array}{l}\text { Route availability } \\
\qquad \text { in } t 1\left(f_{(s)}^{1}\right)\end{array}$ & $\begin{array}{l}\text { Route availability in } \\
\qquad 2\end{array}$ & s \\
\hline \multirow{5}{*}{1} & \multirow{5}{*}{$(0,0,0,0,0,0)$} & $(0,0,0,0,0,0)$ & s1 \\
\hline & & $(0,0,0,0,0,1)$ & s2 \\
\hline & & $(0,0,0,0,1,0)$ & s3 \\
\hline & & $\cdots$ & $\cdots$ \\
\hline & & $(1,1,1,1,1,1)$ & $s 64$ \\
\hline \multirow{5}{*}{2} & \multirow{5}{*}{$(0,0,0,0,0,1)$} & $(0,0,0,0,0,1)$ & $\$ 65$ \\
\hline & & $(0,0,0,0,1,1)$ & $s 66$ \\
\hline & & $(0,0,0,1,0,1)$ & $s 67$ \\
\hline & & $\cdots$ & $\cdots$ \\
\hline & & $(1,1,1,1,1,1)$ & $\$ 96$ \\
\hline$\cdots$ & $\cdots$ & $\cdots$ & $\cdots$ \\
\hline 64 & $(1,1,1,1,1,1)$ & $(1,1,1,1,1,1)$ & s729 \\
\hline
\end{tabular}

\subsubsection{Model formulation of stage 1}

The $1^{\text {st }}$ stage's model for estimate the stocks is formulated as follows:

$$
\text { Min } \quad f 1=\sum_{a} \sum_{i} P C_{a} \cdot S T O C_{a i}
$$

s.t.:

Commodity flow constraints

$X_{\text {aijmt }}^{S} \leq \mathrm{M} R_{i j m t}^{S} Z_{i j}^{m}$

$\sum_{i} \sum_{m}\left(X_{\text {aijm1 }}^{f_{1}(s)}+X_{\text {aijm2 }}^{s}\right) \leq D_{a j}^{s}$

$\forall a \in A ; i \in I ; j \in J ; m \in M ; s \in S ; t \in T$;

$\mathrm{D}_{a j}^{s}-\sum_{i} \sum_{m} X_{a i j m 1}^{f_{1}(s)}=U D_{a j 1}^{f_{1}(s)}$

$\forall a \in A ; j \in J ; f_{1}(s) \in S_{1} ; s \in S$;

$U D_{a j 1}^{f_{1}(s)}-\sum_{i} \sum_{m} X_{a i j m 2}^{s}=U D_{a j 2}^{s}$

$\forall a \in A ; j \in J ; f_{1}(s) \in S_{1} ; s \in S$

Facility capacity and numbers

$\forall a \in A ; j \in J ; f_{1}(s) \in S_{1} ; s \in S ;$

$\overline{\sum_{j} \sum_{m} X_{a i j m 1}^{f_{1}(s)}+\sum_{j} \sum_{m} X_{\text {aijm } 2}^{s}} \leq$ STOC $_{a i}$

$\sum_{a} S T O C_{a i} c_{a} \leq C A P_{i}$

$\forall a \in A ; i \in I ; f_{1}(s) \in S_{1} ; s \in S$;

$\forall i \in I \quad(7)$

Vehicle capacity and numbers

$N_{i j m t}^{S} \leq \mathrm{M} R_{i j m t}^{S} Z_{i j}^{m}$

$\sum_{a} X_{\text {aijmt }}^{s} \cdot c_{a} \leq N_{i j m t}^{s} \cdot \mathrm{vc}^{m}$

$\sum_{a} X_{a i j m t}^{S} \cdot w_{a} \leq N_{i j m t}^{S} \cdot \mathrm{vw}^{m}$

$\forall i \in I ; j \in J ; t \in T ; m \in M ; s \in S$;

$\forall i \in I ; t \in T ; m \in M ; j \in J ; s \in S ;(9)$

Lowest stocking amount constraints

$\forall i \in I ; m \in M ; j \in J ; s \in S ;(10)$

$\frac{\sum_{m} \sum_{i}\left(X_{a i j m 1}^{f_{1}(s)}+X_{a i j m 2}^{s}\right)}{D_{\mathrm{a} j}^{s}} \geq \beta \cdot \alpha_{a j}$

Non-negativity and integrality

$X_{\text {aijmt }}^{s} \geq 0$

$\forall a \in A ; j \in J ; f_{1}(s) \in S_{1} ; s \in S ;(11)$

STOC $_{a i} \geq 0$

Real number.

$N_{i j m t}^{S} \geq 0$

Real number.

Integer.

In the 1st stage, the objective function (1) is the sum of the procurement cost to be minimized. Constraint (2) means that the transportation happens only when the route is available and the post-time is smaller than the limited 
response time $\delta$. Constraint (3) gives the upper-bound on a transported amount of each commodity. Constraint (4) shows the relationship among the demand, satisfied demand and the unsatisfied demand of each time period. Constraint (5) means the total amount of transported commodities should be less than or equal to the stocking amount. Constraint (6) limits the stocking amount by the capacity of the distribution center. Constraint (7) means the vehicle is usable only when the route is available and the post-time is smaller than the limited response time $\delta$. Constraint (8) limits the effective transport-times by vehicle numbers which is prepared previously and additionally. Constraint (9) (10) limits the transported commodities by the loading capacity and volume of each vehicle. Constraint (11) is the lowest satisfaction proportion of each disaster area and each commodity. (In constraint (11), when $\beta * \alpha_{a j}>1$, then make $\beta=1 / \alpha_{a j}$ ) Constraint (12), (13), (14) means that the stocking amount, transported amount should be positive; transporting time should be a positive integer.

Through the 1st stage we can forecast the stocking amount of each commodity which is the most appropriately under each scenario. Our objective function is going to make the stocking cost as small as possible.

\subsection{Stage 2 - delivering planning}

In stage 2, we want to know the best dispatching route and allocation plan of the post-disaster period. As the government can grasp the route condition just after the disaster occurs, $f_{1}(s)$ can be decided shortly at the beginning of this period. So we can use this route condition to estimate the route condition later. In stage 2 , the objective is to minimize the total cost including the transportation cost, the vehicles rental cost, the fuel cost and the penalty cost of the unsatisfied demands. Here the penalty cost is used to raise the average satisfied proportion. Therefore, we can find an appropriate plan to dispatch these stocking commodities.

When disaster happens, a number of vehicles are needed to dispatch the relief commodities. However, it is a difficult thing to rent such large number of vehicles in a short time. Here we supposed that only a few number of vehicles can be rent at the ordinary rental price. Rest of vehicles can be added but at a higher price than before.

Meanwhile, in order to use the vehicles fully, one vehicle can travel several times between the distribution center and disaster area. The available travel times of each vehicle $Q_{i m}^{s}$ are limited by the number of available vehicles $Q V_{m}^{s}$, travel distance $L_{i j}$, the length of each time period $\delta$ and the average speed of each vehicle's type. Each type of vehicle has a maximum additional number $\operatorname{Max}_{m}$. These can also be presented by the equations below:

where $Q V_{m}^{s} \leq \operatorname{Max}_{m}$.

$$
Q_{i m}^{s}=Q V_{m}^{s} \cdot\left[\delta /\left(\max \left(L_{i j} / v^{m}\right)\right)\right]
$$

\subsubsection{Scenario generation for stage 2}

In the post-disaster phase, the route condition just after the disaster $f_{1}(s)$ was known already. Therefore,

$$
P_{s}=P\left(s_{1}\right) \cdot P\left(s \mid s_{1}\right)=P\left(s \mid s_{1}\right)
$$

\subsubsection{Model formulation of stage 2}

The $2^{\text {nd }}$ stage's model for delivering planning is formulated as follows:

$$
\text { Min } f 2=\sum_{s} p_{s}\left[\sum_{m} \sum_{i} \sum_{j}\left(\left(N_{i j m 1}^{f_{1}(s)}+N_{i j m 2}^{s}\right) \cdot T C_{m} \cdot L_{i j}+\mathrm{QC}_{m} \cdot Q V_{m}^{s}\right)+\sum_{j} \sum_{a} U D_{a j 2}^{s} \cdot \pi_{a}\right]
$$

\section{Commodity flow constraints}

$$
\begin{array}{lr}
\frac{\text { S.t. }}{X_{\text {aijmt }}^{s} \leq \mathrm{M} R_{i j m t}^{s} Z_{i j}^{m} \quad \forall a \in A ; i \in I ; j \in J ; m \in M ;} \quad t=1, s=f_{1}(s) ; t=2, s \in S ; \\
\sum_{i} \sum_{m}\left(X_{a i j m 1}^{f_{1}(s)}+X_{a i j m 2}^{s}\right) \leq D_{a j}^{s} & \forall a \in A ; j \in J ; s \in S ; \\
\mathrm{D}_{a j}^{s}-\sum_{i} \sum_{m} X_{a i j m 1}^{f_{1}(s)}=U D_{a j 1}^{f_{1}(s)} & \forall a \in A ; j \in J ; s \in S ; \\
U D_{a j 1}^{f_{1}(s)}-\sum_{i} \sum_{m} X_{a i j m 2}^{s}=U D_{a j 2}^{s} & \forall a \in A ; j \in J ; s \in S ;
\end{array}
$$

\section{Facility capacity and numbers}

$\sum_{j} \sum_{m} X_{\text {aijm1 }}^{f_{1}(s)}+\sum_{j} \sum_{m} X_{\text {aijm2 }}^{s} \leq$ STOC $_{a i}$

$\forall a \in A ; i \in I ; s \in S$

\section{Vehicle capacity and numbers}

$N_{i j m t}^{s} \leq \mathrm{M} R_{i j m t}^{s} Z_{i j}^{m} \quad \forall i \in I ; j \in J ; m \in M$

$\sum_{i} \sum_{j} N_{i j m t}^{s} \leq N_{i m}+Q_{i m}^{s}$

$Q_{i m}^{s}=Q V_{m}^{s} \cdot\left[\delta /\left(\max \left(L_{i j} / v^{m}\right)\right)\right]$

$Q V_{m}^{s} \leq \operatorname{Max}_{m}$

$$
\begin{array}{r}
t=1, s=f_{1}(s) ; t=2, s \in S ; \\
\forall i \in I ; t \in T ; m \in M ; s \in S ; \\
\forall i \in I ; j \in J ; t \in T ; m \in M ; s \in S ; \\
\forall m \in M ; s \in S ;
\end{array}
$$


$\sum_{a} X_{a i j m t}^{s} \cdot c_{a} \leq N_{i j m t}^{s} \cdot \mathrm{vc}^{m}$

$\sum_{a} X_{\text {aijmt }}^{s} \cdot w_{a} \leq N_{\text {ijmt }}^{s} \cdot \mathrm{vw}^{m}$

$\forall i \in I ; m \in M ; j \in J ; t \in T ; s \in S ;(26)$

$\forall i \in I ; m \in M ; j \in J ; t \in T ; s \in S ;(27)$

Lowest satisfaction proportion constraints

$\mathrm{X}_{\mathrm{f}}^{\mathrm{f}_{1}(\mathrm{~s})}$

$\frac{\mathrm{X}_{\mathrm{aijm} 1}^{\mathrm{f}_{1}(\mathrm{~s}}}{\mathrm{D}_{\mathrm{aj}}^{\mathrm{s}}} \geq \varphi \cdot \alpha_{\mathrm{aj}}$

$\forall a \in A ; j \in J ; s \in S ; \varphi<1$

$\frac{\sum_{m} \sum_{i}\left(X_{a i j m 1}^{f_{1}(s)}+X_{a i j m 2}^{s}\right)}{D_{a j}^{s}} \geq \alpha_{a j}$

$\forall a \in A ; j \in J ; s \in S$;

$\underline{\text { Unit penalty cost }}$

$\forall a \in A ;$

$\underline{\text { Non-negativity and integrality }}$

$X_{\text {aijmt }}^{S} \geq 0$

Real number; (31)

$N_{i j m t}^{s}, Q V_{i m}^{s} \geq 0$

Integer. (32)

In the 2nd stage, the objective function $\mathrm{f} 2$ minimizes the sum of rental cost for hiring vehicles, the fuel cost for vehicles and the penalty cost for unsatisfied demand. New constraints are added. Constraint (23) limits the available transporting times by the available number of each vehicles. Constraint (24) shows the relationship between the available transporting times of each vehicle type and available vehicle's number. Constraint (25) means that the additional vehicle's number is limited by its upper bound. Constraints (28) is the lowest satisfaction proportion constraint for the first time period, which limits the satisfied proportion in the $1^{\text {st }}$ time period with the lowest bound value of $\varphi \cdot \alpha_{a j}$. Constraint (29) is the lowest satisfaction proportion constraints for the whole delivering process. Equation (30) shows the unit penalty cost can be adjusted by the value of $\eta$. Other constraints are the same meaning with constraints in stage 1. From stage 2, the proper dispatching plan for post-disaster period can be decided.

\section{Case study}

\subsection{Test case description}

In this section, we take the case constructed of the Si-chuan Province in China, which is located at the Earth-quake-prone zone. 6 disaster areas are identified from the most seriously affective areas and choose 1 city as the distribution center. The map of Relief Distribution Center (RDC) and Disaster Areas (DAs) is showed in Fig. 3 (Each DA is represented by alphabet from ' $A$ ' to ' $F$ '). In this case study, 4 types of relief commodities are considered- Food, Water, Tent and Medicine. Table 2 shows the properties of each commodity. In the rescue period, 2 types of vehicles are used - helicopter and truck, and the features of each vehicle type shows in Table 3.

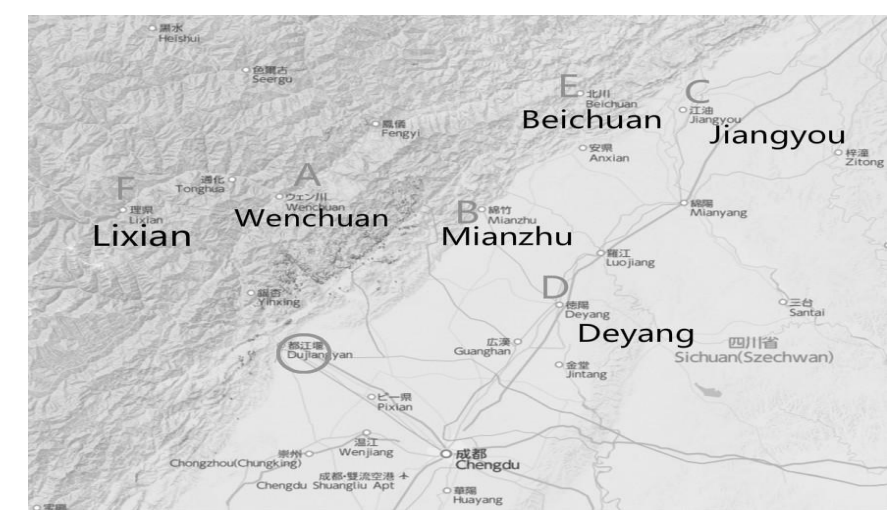

Fig. 3 Map of disaster areas and distribution center 
Table 2 Features of each commodity

\begin{tabular}{c||cccc}
\hline & $\begin{array}{c}\text { Unit } \\
\text { price } \\
(\$)\end{array}$ & $\begin{array}{c}\text { Unit } \\
\text { weight } \\
(\mathrm{kg})\end{array}$ & $\begin{array}{c}\text { Unit } \\
\text { volume } \\
\left(\mathrm{m}^{\wedge} 3\right)\end{array}$ & $\begin{array}{c}\text { Serving } \\
\text { number } \\
(\text { people) }\end{array}$ \\
\hline Food(box) & 12 & 4 & 0.054 & 5 \\
\hline Water(tank) & 4.5 & 18 & 0.054 & 3 \\
\hline Tent(unit) & 90 & 40 & 0.2 & 15 \\
\hline Medicine(box) & 47 & 5 & 0.1887 & 10 \\
\hline
\end{tabular}

Table 3 Features of each vehicle type

\begin{tabular}{c||ccccc}
\hline $\begin{array}{c}\text { Vehicle } \\
\text { type }\end{array}$ & $\begin{array}{c}\text { Transpor } \\
\mathrm{t} \text { cost } \\
(\$ / \mathrm{km})\end{array}$ & $\begin{array}{c}\text { Weight } \\
\text { capacity } \\
(\mathrm{kg})\end{array}$ & $\begin{array}{c}\text { Volume } \\
\text { capacity } \\
\left(\mathrm{m}^{\wedge} 3\right)\end{array}$ & $\begin{array}{c}\text { Velocity } \\
(\mathrm{km} / \mathrm{h})\end{array}$ & $\begin{array}{c}\text { Rental } \\
\text { cost } \\
(\$ / 24 \mathrm{~h})\end{array}$ \\
\hline Heli. & 2.61 & 4100 & 45 & 252 & 28800 \\
\hline Truck & 0.003 & 14000 & 1240 & 80 & 900 \\
\hline
\end{tabular}

\subsection{Determination of the lowest satisfied proportion}

For each disaster area, there are various factors can affect the impact of the earthquake. There are several main factors which are distance from epicenter, population density, age of the residents, urbanization rate, density of buildings, geology, education and planning. In this study, we are going to evaluate the 6 disaster areas' rescue degree by focusing on these 4 factors: the population density, dependent ratio of aged population, distance from the epicenter and the urbanization rate of the six disaster areas.

Then we calculate the rescue degree of 6 disaster areas by the TOPSIS method. The procedure can be summarized as:

Step 1. Create an evaluation matrix consisting of 6 alternatives and 4 criteria

Step 2. Normalization of the evaluation matrix

Step 3. Calculate the weighted normalized decision matrix

Step 4. Determine the worst and the best alternative value

Step 5. Calculate the distance between the target alternative and the worst condition.

Step 6. Calculate the similarity to the worst condition

Step 7. Rank the alternatives according to step 6.

Step 8 . Then we can get the lowest satisfaction degree by the equation .

\section{Numerical results}

In this case study, first we code each scenario explained in section 2.3.1 on Python 2.7.6. The solving time is less than 2 minutes. The 2-stage mathematical model presented in section 2 is realized on GAMS 24.1.3 and run by CPLEX12.5.1.0 solver on an Intel® CoreTM i7-3770 Dual Processor with 24 GB RAM and 3.40 GHz CPU. The computation time of each test problem is less than 1 mi-nute.

\subsection{Result of stocking estimation}

At first, we run the model of stage 1 demonstrated in section 2.3.2 under capacity of each distribution center of $14000 \mathrm{~m}^{3}$; maximum response time of 6 hours; lowest proportion of satisfied stated in section 3.2; extra stocking coefficient of $1,1.5,2,2.5,3$, and 3.1 for commodity typed 1 to 4 . The result of how does extra stocking coefficient affects the stocking amount is showed in Table 4.

Table 4 Stocking amount of each relief commodity (unit)

\begin{tabular}{cllcc}
\hline$\beta$ & $\mathrm{a} 1$ & $\mathrm{a} 2$ & $\mathrm{a} 3$ & $\mathrm{a} 4$ \\
\hline 1.0 & 54990 & 67335 & 5985 & 5050 \\
\hline 1.5 & 75729 & 99875 & 8978 & 7575 \\
\hline 2.0 & 84233 & 114815 & 11970 & 10100 \\
\hline 2.5 & 86902 & 123094 & 14055 & 12625 \\
\hline 3.0 & 87374 & 124243 & 15308 & 14981 \\
\hline 3.1 & \multicolumn{3}{c}{ INFEASIBLE } \\
\hline
\end{tabular}


From Table 4 we can see that with the increasing of $\beta$, the stocking amount of each commodity is increasing. We can also know that the model turns to be infeasible when $\beta$ is 3.1. When $\beta$ becomes larger than 3.1, constraint (6) and (11) conflicts each other. In other words, the volume of all the relief commodities exceeds the distribution center's capacity.

\subsection{Delivering plans with different extra stocking coefficient}

Next, model of stage 2 which demonstrated in section 2.4.1 is run under stocking amounts showed in Table 5; the unit penalty cost of $37.80,12.15,162.00,63.45$ for commodities 1 to 4 ; the fuel costs of helicopter and truck are $2.61 \$ / \mathrm{km}, 0.00295 \$ / \mathrm{km}$; the rental costs of helicopter and truck are $28800 \$ /$ day, $900 \$ /$ day,

With different value of $\beta$, not only the procurement cost in stage 1 changes, but also costs in stage 2 are changing as well. To illustrate this clearly, here is an example. When $f_{1}(s)=(1,0,1,1,0,0)$, each part of the total cost is shown in Table 5.

To see the relationship between stage 1 and stage 2 clearly, Fig. 3 shows the average satisfied proportion of each disaster area when the Stocking extra coefficient $\beta$ changes from 1 to 3 in scenario 636 (which route condition is $(1,0,1,1,0,0) \rightarrow(1,0,1,1,0,1))$. With the increasing of $\beta$, most disaster areas are served more relief commodities.

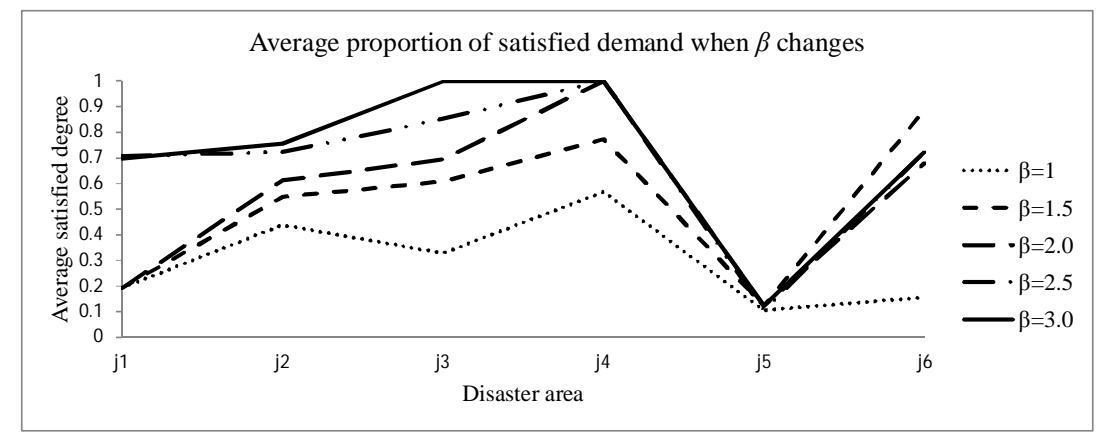

Fig. 3 Average satisfied proportion of each disaster with Different value of $\beta$

Table 5 Costs variation with different $\beta$

\begin{tabular}{|c|c|c|c|c|c|}
\hline & Stage 1 & & Stage & & $\begin{array}{l}\text { Stage } \\
1 \& 2\end{array}$ \\
\hline$\beta$ & $\begin{array}{l}\text { Procurement cost } \\
(\$)\end{array}$ & $\begin{array}{c}\text { Rental } \\
\text { cost } \\
(\$)\end{array}$ & $\begin{array}{c}\text { Trans. } \\
\text { cost } \\
(\$)\end{array}$ & $\begin{array}{c}\text { Penalty } \\
\text { Cost } \\
(\$)\end{array}$ & $\begin{array}{c}\text { Total } \\
\text { Costs } \\
(\$)\end{array}$ \\
\hline 1.0 & 1738935 & 400400 & 32869 & 4669300 & 6841504 \\
\hline 1.5 & 2522261 & 435614 & 43354 & 2844952 & 5846181 \\
\hline 2.0 & 3079562 & 452552 & 44513 & 1696941 & 5273568 \\
\hline 2.5 & 3455142 & 456629 & 44968 & 1003947 & 4960686 \\
\hline 3.0 & 3689502 & 457765 & 45071 & 629877 & 4822215 \\
\hline
\end{tabular}

\subsection{Delivering plans in different scenarios}

In stage 2, to learn how does scenario effects the whole relief planning, we selected 3 different route conditions of the 1 st time period as examples. The worst route situation $(0,0,0,0,0,0)$ - none of the route is available for trucks; an ordinary route situation $(1,0,1,1,0,0)$ - part of the routes are available for trucks, and the best route condition $(1,1,1,1$, $1,1)$ - all of the route is available for trucks. Maximum additional helicopter's number in cases $1,2,3$ are set as 20,15 and 15, respectively. The procurement cost, rental cost, transportation cost, total cost of these 3 cases is shown in Table 6.

In order to satisfy each disaster area's demands, the rental cost of vehicles and the fuel cost are affected directly by the route conditions. For example, case 1 spends the most because of the high rent cost and fuel cost of helicopters. On the contrary, case 3 spends the least just as the good route condition which means we can meet the demands only by trucks.

In Fig. 4, the bottom line presents the lowest satisfied degree line. Even under the worst route condition, this model can offer more relief commodities than the lowest degree, which is reasonable in real life. The top line in Fig. 4 
Table 6 Costs with different scenarios $(\beta=3)$

\begin{tabular}{cccccc}
\hline Stage 1 & \multicolumn{5}{c}{ Stage 2} \\
\hline $\begin{array}{c}\text { Case } \\
\text { NO. }\end{array}$ & $\begin{array}{c}\text { Procurement cost } \\
(\$)\end{array}$ & $\begin{array}{c}\text { Rental } \\
\text { cost } \\
(\$)\end{array}$ & $\begin{array}{c}\text { Trans. } \\
\text { cost } \\
(\$)\end{array}$ & $\begin{array}{c}\text { Penalty } \\
\text { Cost } \\
(\$)\end{array}$ & $\begin{array}{c}\text { Total } \\
\text { Costs } \\
(\$)\end{array}$ \\
\hline 1 & 3689502 & 486822 & 55529 & 754298 & 4986151 \\
\hline 2 & 3689502 & 457765 & 45071 & 629877 & 4822215 \\
\hline 3 & 3689502 & 35100 & 959 & 430501 & 4156062 \\
\hline
\end{tabular}

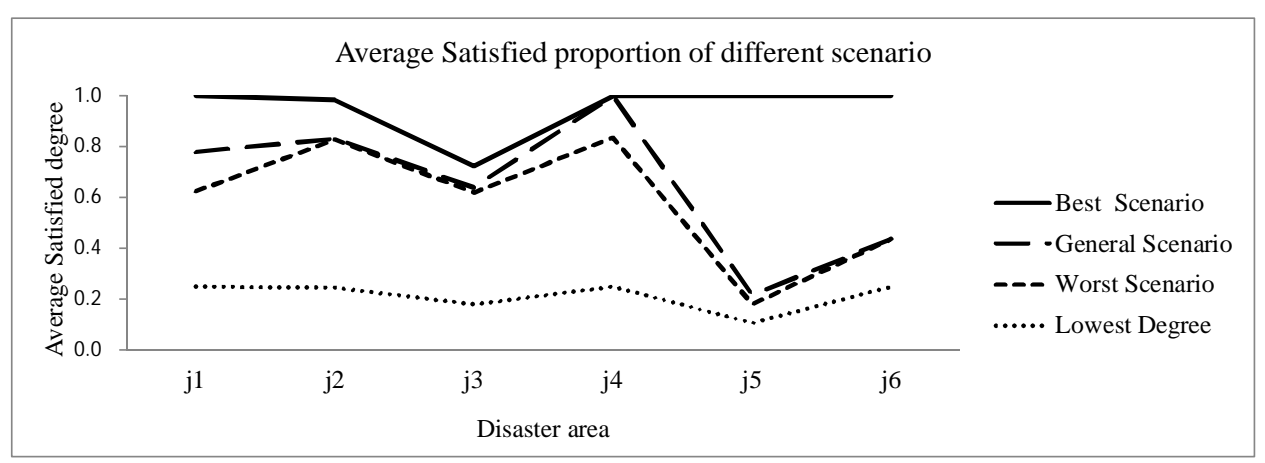

Fig. 4 Average satisfied proportion of 3 cases

is the average satisfied proportion under the best route condition. Apart from disaster area $j 3$ (Jiangyou), the rest areas can receive almost the demands. One of the reason why $j 3$ (Jiangyou) is provided less than other disaster areas is $j 3$ (Jiangyou) is the furthest from the distribution center. The other reason is because of the amount of the total transported commodities are limited by the stocking amounts.

\section{Conclusions}

This study aimed to contribute to the existing literature by developing a new two-stage stochastic network flow model under practical assumptions that are rarely considered in previous similar papers, such as the fleet size, multiperiod of disaster relief operations, and a variety of un-certain data. A set of scenario is used which is based on all possible path combinations. As disasters are complex and unpredictable, the solutions provided by this mathematical model may not be fulfilled completely. However, the decision makers can adapt this 2 -stage stochastic model into different disaster events by adjusting the value of the extra stocking coefficient $\beta$ and the penalty coefficient $\eta$. For decision makers, they should weigh and consider the balance of the money, human resource and the mortality when disaster happens. This may be related with the severity of the disaster, the development condition of one country, rescue difficulty and so on.

To some natural disasters such as earthquakes and hurricanes, geographical condition has the greatest impact in all the criteria. It can affect the frequency of disaster happens, the rescue difficulty and even the reconstruction of each disaster area. Therefore, to combine some geographic data such as the Digital Elevation Model (DEM) data and other digitized topographic conditions with our model would be a challenging future work. With the scale of problem becoming larger, to solve the models more efficiently should also be considered.

\section{References}

Assari, A., Mahesh, T., Assari, E., Role of public participation in sustainability of historical city: usage of TOPSIS method. Indian Journal of Science and Technology, Vol.5, No.3 (2012b), pp. 2289-2294. 
Carmen, G.R., Mark, A.T., Pre-positioning and dynamic delivery planning for short-term response following a natural disaster. Socio-Economic Planning science, Vol.44, No.1 (2012), pp. 46-54.

Douglas A, Alistair C.Alfredo M., Stochastic network models for logistics planning in disaster relief. European Journal of Operational Research, Vol.255, No.1 (2016), pp. 187-206.

Duran, S., Ergun, O., Keskinocak, P., Swann., J.L. Humanitarian Logistics: Advanced Purchasing and Pre-Positioning of Relief Items. Handbook of global logistics (2012), pp. 447-462, Springer New York.

Greene, R., Devillers, R., Luther, J.E., Eddy, B.G. GIS-based multi-criteria analysis. Geography Compass, Vol.5, No. 6 (2011), pp. 412-432.

Gonçalves P. Balancing provision of relief and recovery with capacity building in humanitarian operations. Operation Management Research, Vol.4, No.1 (2011), pp. 39-50.

Haghani A., Oh S.C. Formulation and solution of a multi-commodity, multi-modal network flow model for disaster relief operations. Transp. Res. A Policy Pract, Vol.30, No.3 (1996), pp. 231-250.

Hwang, C.L.; Yoon, K. Multiple Attribute Decision Making: Methods and Applications (1981), pp. 128-141, Springer-Verlag, New York

Hwang, C.L., Lai, Y.J., Liu, T.Y. A new approach for multiple objective decisions making. Computers and Operational Research, Vol.20, No.8 (1993), pp. 889-899.

Luk N, Van W.Alfonso J., Using OR to adapt supply chain management best practices to humanitarian logistics. International transactions in operational research, Vol. 19, No. 1-2 (2010), pp. 307-322.

Opit, P.F., Nakade, K. Distribution model of disaster relief supplies by considering route availability. Japan Industria Management Association, Vol.66, No.2E (2015), pp. 154 - 160.

Özdamar L, Ekinci E, Küçükyazici B, Emergency logistics planning in natural disasters. Annals of Operations Research, Vol.29, No.1 (2004), pp. 217-245.

Sheu MS, Hsu CC, Vulneralibity study of school buildings in Taiwan before and after retrofitting. The Role of Engineering and Technology (1995), pp. 109-120, Urban Disaster Mitigation.

Smith E., Wasiak J., Sen A., Archer F. Three Decades of Disasters: A Review of Disaster-Specific Literature from 1977-2009, Vol.24, No.4 (2009), pp. 306-311, Prehospital and Disaster Medicine.

Yajie, L, Tao, Z. Stochastic programming approach for earthquake disaster relief mobilization with multiple objectives. Journal of Systems Engineering and Electronics, Vol.24, No. 4 (2013), pp. 642-654.

Yan SY, Remote sensing application in the geologic disaster evaluation of Wenchuan earthquake. Journal of Hebei University of Engineering (Natural Science Edition), Vol.26, No.1 (2009), pp. 76-80.

Yoon, K.P.; Hwang, C, Multiple Attribute Decision Making: An Introduction (1995), pp. 38-45, SAGE Publications, California.

Zavadskas, E.K., Zakarevicius, A., Antucheviciene, J., Evaluation of Ranking Accuracy in Multi-Criteria Decisions. Informatics, Vol.17, No.4 (2006), pp. 601-618. 